\title{
Transparency and the Therapeutic Goods Administration
}

\section{Ken Harvey \\ Adjunct associate professor School of Public Health \\ La Trobe University \\ Melbourne}

Key words

advertising, complementary medicines, drug regulation

Aust Prescr 2013:36:110-1
The Therapeutic Goods Administration (TGA)

regulates medicines and devices in Australia. In 2010 and 2011 there were major reviews of the TGA in response to health professional and consumer concerns. These culminated in several reports, including two government papers:

- 'TGA Reforms: A blueprint for TGA's future' (December 2011)

- 'Delivering reforms - Implementation plan for TGA Reforms: A blueprint for TGA's future' (July 2012). ${ }^{2}$

These documents outline a four-year timetable of incremental reform aimed at increasing the transparency of TGA regulatory processes and decisions, and enhancing public trust in the safety and quality of therapeutic goods. Several reforms have already been implemented while many others are underway. 3,4

An Australian Therapeutic Goods Advisory Council ${ }^{5}$ has been established to encourage wider community input into the future direction of the TGA, including the implementation of the reforms. It has held two meetings to date. The Council website includes an email contact address which could be used to communicate ongoing concerns to council members.

The TGA website (www.tga.gov.au) has been improved to provide better access for health professionals, consumers and industry. It is now possible to search the TGA's database of adverse

\section{From the Editor}

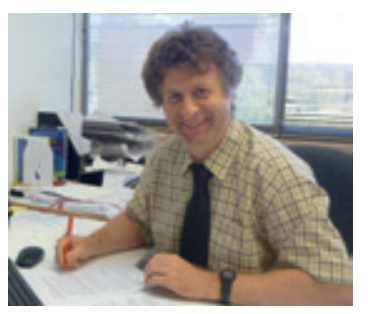

Mark McFarlane and Krispin Hajkowicz tell us that inappropriate antibiotic use has probably contributed to the increasing incidence of infections with Clostridium difficile. One strategy to tackle this problem is antibiotic stewardship which is explained by Duncan McKenzie, Matthew Rawlins and Chris Del Mar.

Severe cases of $C$. difficile may require resection of the bowel. Siddharth Sood, Francine Tanner and Adam Testro advise how to prescribe for patients with a reduced intestinal length. Gastrointestinal adverse events commonly occur with some of the new targeted anticancer drugs. However, Winston Liauw points out that these drugs do not have the antiproliferative toxicity of chemotherapy for cancer.

In addition to their use by patients with cancer, opioids are being prescribed for chronic pain. However, Milton Cohen recommends against using certain formulations. If the public are to have trust in regulators, there needs to be transparency about their work. Ken Harvey reports on the progress of the Therapeutic Goods Administration towards greater transparency in Australian drug regulation. events from medicines, to access product information and consumer medicines information, and see product alerts and recalls. You can search the Australian Register of Therapeutic Goods (ARTG) to see if a product is currently authorised for supply in Australia and view its ingredients. Although there is a summary of the product, for listed complementary medicines the information is provided by the sponsor without independent assessment by the TGA. This information may not be in accordance with scientific evidence.

Other useful information is also available on the TGA website, but can be difficult to find. An example is a small list of registered complementary medicines that have been evaluated by the TGA for safety, quality and efficacy. ${ }^{6}$ Surprisingly this list contains one formulation of glucosamine hydrochloride. When the TGA was queried as to why this product was registered, it noted that the product was evaluated by the standards of the time (1999). Its inclusion on the TGA list highlights a fundamental problem of TGA registration of both complementary medicines and prescription medicines. While safety information is updated by the sponsor and the TGA, amending other product information, such as a change of dose interval, requires a formal submission from the sponsor which they may not feel is worthwhile to do.?

Another example of useful information (found under the headings 'Industry, Complementary medicines, Regulatory decisions and notices') is a list of cancellations from the ARTG following compliance review. Ironically, cancelled products can be quickly relisted by the sponsor, for example by making minor changes to the label. This practice was highlighted by a recent $A B C$ TV program, 'The Checkout'.

The outcomes of some TGA investigations into advertising complaints about complementary medicines referred from the Complaints Resolution Panel (CRP) are also available. ${ }^{9}$ Some of these 'outcomes' merely record years of continued noncompliance with CRP and/or TGA 'Regulation 9 orders', for example, Bayer's Berocca Performance (Complaint No. 2010-10-017), and Homeopathy Plus (Complaint No 2011/05/004). This highlights the current impotence of the TGA with respect to imposing timely and effective sanctions on advertising violations, although there is a proposal to enhance the sanctions. ${ }^{10}$ 
The CRP has stated, 'Regulation 9 orders issued by TGA for advertising complaint determinations finalised by the Panel after 1 November 2010 will be publicised on the TGA's website'. In fact, since November 2010 at least 88 complaints have been referred to the TGA by the CRP because of non-compliance, of which only 14 have an 'outcome' recorded on the TGA website. In response to a query about this matter the TGA said, 'As part of the implementation of the Transparency Review, consideration is being given to publishing the outcome of all advertising complaint investigations in the future'.

Australian Public Assessment Reports for prescription medicines (AusPARs) summarise the evaluation process that led the TGA to approve or not approve a drug for use in Australia. They can be found using the search function. There has been some concern that since AusPARs were introduced the TGA has stopped publishing the resolutions of the Advisory Committee on Prescription Medicines. Another problem is that a drug can appear on the Australian market before the AusPAR is available.

In short, a good start has been made, and there are many more reforms to come. The implementation of some reforms will be protracted as regulatory impact statements and amendments to the Therapeutic Goods Act 1989 or TGA regulations will be required. $<$

Dr Harvey has represented consumer organisations on the TGA Transparency Review Panel, the TGA informal working group on the regulation of complementary medicines, and the Working Group on Promotion of Therapeutic Products, Department of Health and Ageing.

\section{REFERENCES}

1. Therapeutic Goods Administration. TGA reforms: A blueprint for TGA's future. Canberra: Department of Health and Ageing; 2011. www.tga.gov.au/about/tga-reforms-blueprint.htm [cited 2013 Jul 10]

2. Therapeutic Goods Administration. Delivering reforms - Implementation plan for TGA reforms: A blueprint for TGA's future. Canberra: Department of Health and Ageing; 2012

www.tga.gov.au/about/tga-reforms-blueprint-implementation.htm [cited 2013 Jul 10]

3. Therapeutic Goods Administration. TGA reforms: A blueprint for TGA's future: Progress report as at 31 December 2012. Canberra: Department of Health and Ageing; 2013 Feb.

www.tga.gov.au/about/tga-reforms-blueprint-progress-121231.htm [cited 2013 Jul 10]

4. Therapeutic Goods Administration. TGA external communication and education framework: Priorities and projects 2013-2015. Canberra: Department of Health and Ageing; 2012.

www.tga.gov.au/about/tga-communication-framework-1315.htm [cited 2013 Jul 10]

5. Therapeutic Goods Administration. Australian Therapeutic Goods Advisory Council. Canberra: Department of Health and Ageing; 2013. www.tga.gov.au/about/committees-atgac.htm [cited 2013 Jul 10]
6. Therapeutic Goods Administration. List of evaluated registered complementary medicines. Canberra: Department of Health and Ageing; 2013.

www.tga.gov.au/industry/cm-basics-regulation-evaluation.htm [cited 2013 Jul 10]

7. Dowden J. Product information past perfect. Med J Aust 2007;186:51-2. wWw.mja.com.au/journal/2007/186/2/product-information-past-perfect [cited 2013 Jul 10]

8. Australian Broadcasting Corporation. Nicole Kidman joins The Checkout + dodgy Swisse labelling. The Checkout (TV program). Episode 5. 2013 Apr 17. http://youtu.be/12ww26sQF7E [cited 2013 Jul 10]

9. Therapeutic Goods Administration. Decisions in relation to complaints about advertisements. Canberra: Department of Health and Ageing; 2013. www.tga.gov.au/industry/advertising-reg9.htm [cited 2013 Jul 10]

10. Therapeutic Goods Administration. Consultation Regulation Impact Statement. Regulating the advertising of therapeutic goods to the general public. Version 4.6. Canberra: Department of Health and Ageing; 2013 www.tga.gov.au/pdf/consult/consult-advertising-ris-130531.pdf [cited 2013 Jul 10]

\section{Letters to the Editor}

\section{Safe and effective use of lithium}

Editor, - Gin Malhi, Michelle Tanious, Danielle Bargh, Pritha Das and Michael Berk have provided an excellent article on the safe and effective use of lithium (Aust Prescr 2013;36:18-21). They make reference to a 'sustained slow-release formulation which may be better tolerated by some patients'. Only two of four lithium-containing compounds listed in MIMS are suitable for lithium treatment. These are lithium carbonate and are listed as Lithicarb and Quilonum SR. Lithicarb in a new gluten-free formulation is not sustained release. Quilonum SR is commonly believed to be a sustained-release preparation, but it is not. The manufacturer states 'While Quilonum SR tablets are designed to reduce fluctuations in plasma lithium concentrations, the formulation is not prolonged release in the usual sense'. Lithicarb is a $250 \mathrm{mg}$ scored tablet readily permitting fine tuning of dose, but normally given twice a day. Quilonum SR tablets should be given every 12 hours as detailed in the product information. The $450 \mathrm{mg}$ preparation may be suitable for many patients, but the larger dose means finetuning the dose may be difficult. At present we have no sustained-release lithium preparation in Australia.

John Tiller Professor of Psychiatry Albert Road Clinic

Melbourne
The Editorial Executive Committee welcomes letters, which should be less than 250 words. Before a decision to publish is made, letters which refer to a published article may be sent to the author for a response. Any letter may be sent to an expert for comment. Letters are usually published together with their responses or comments in the same issue. The Committee screens out discourteous, inaccurate or libellous statements and sub-edits letters before publication. Authors are required to declare any conflicts of interest.The Committee's decision on publication is final. 